\title{
LIVRO E SOCIEDADE NO RIO DE JANEIRO $(1808-1821)(*)$.
}

\author{
MARIA BEATRIZ NIZZA DA SILVA \\ do Departamento de História da Faculdade de Filo- \\ sofia, Letras e Ciências Humanas da Universidade de
} São Paulo.

São numerosos os trabalhos que se propõem estudar as relações entre literatura e sociedade como se o conceito de literatura fosse claro e indiscutível. $\mathrm{E}$ isto acontece porque não se põe em dúvida o estatuto literário de um número relativamente restrito de grandes obras, que são precisamente as analisadas por teóricos como Lukács, Goldmann e outros continuadores da mesma linha de análise. Ora, se estudarmos historicamente o próprio termo literatura veremos que ele possui uma grande variedade de empregos e que o seu conteúdo semântico é tão variado quanto incoerente. Em 1813 era ainda possível ao dicionarista Antônio Morais Silva ignorar a própria palavra literatura, muito embora no seu dicionário constassem os adjetivos "literário" e "literato", dotados de um significado muito mais amplo do que hoje possuem. Literário era tudo o que respeitava às "letras, ciências, estudos, erudições" e "orbe literário" por exemplo significava o conjunto dos "homens doutos".

Se a especificidade da literatura é algo que os teóricos têm pretendido isolar sem nunca o conseguirem, se, apesar de todo o interesse despertado pelos estudos de Vladimir Propp sobre o conto maravilhoso russo, a chamada literatura oral ainda se encontra marginalizada em relação à literatura escrita, por que razão não poderemos nós procurar descobrir as relaçōes entre livro e sociedade, se estas se nos afiguram mais variadas e menos problemáticas do que aquelas que implicam a partilhą entre o literário e o não literário?

(*). - Comunicação apresentada na 3.a Sessão de Estudos, no dia 7 de julho de 1972 (Nota da Redação). 
O livro tornou-se portanto o nosso objeto, mas só depois de passar por uma espécie de "desacralização" que consiste, por assim dizer, em lhe retirar o caráter individual para o inserir numa massa. Se pretendemos realmente atingir fenômenos coletivos, tocar os centros de interesse e as preocupações dos grupos sociais aos quais chega a cultura escrita, á preciso superar o nível da mensagem individual e considerar o livro como um fato social que é constituido e determinado por atividades e atitudes coletivas. O livro não se reduz aos atos individuais de escritura e leitura da obra. Ele é vendido, comprado e colecionado; é aprovado ou censurado por críticos profissionais e pelo público (ou públicos); é retido pela memória coletiva ou lançado no esquecimento; é classificado segundo as articulações conceptuais de uma época; entra em relações complexas com a máquina estatal. Importa portanto ao historiador da cultura levar em conta todas estas múltiplas facetas do livro.

Num artigo publicado em 1971 e intitulado $A$ outra sociologi $i$ da literatura referimo-nos à necessidade de se abandonar a perspectiva valorativa do estudo das grandes obras literárias para se passar à descrição e análise da denominada sub-literatura por ser esta precisamente a que se encontra mais próxima da sociedade que a produziu e consumiu (1). Ampliando agora essa problemática e abandonando o campo restrito daquilo que hoje se denomina literatura (2), preocupamo-nos com o livro e com o seu processo de produção, distribuição e consumo numa determinạda sociedade.

O Rio de Janeiro, desde o estabelecimento da Impressão Régia até ao regresso da Corte para Lisboal em 1821, forneceu-nos o material de pesquisa. E isto por razões de vária ordem: em primeiro lu. gar, para se estudar o livro como mercadoria, deve-se escolher um meio urbano, pois se torna muito mais difícil ao historiador avaliar a difusão das obras em meio rural; em segundo lugar é aconselhável dar a preferência a um meio urbano que produza livros e que portanto não esteia totalmente dependente da sua importação, o que, no início do século passado, só se verificava no Rio de Janeiro e Bahia; em terceiro lugar é conveniente escolher um período em que a produção, distribuiçã̃o e consumo das obras não sejam de tal modo intensas que impeçam ou dificultem a recolha do material por um só pesquisador.

(1). - Suplemento Literário de $O$ Estado de São Paulo, de 30 de maio de 1971 .

(2). - Ver Robert Escarpit; "La définition du terme littérature", i.) $L e$ littéraire et le social, Paris, 1970. 
A primeira balisa cronológica, 1808 - criação da Real Oficina Tipográfica - não precisa de ser justificada. Ela impõe-se naturalmente. O mesmo não acontece com a segunda, 1821, data do regresso da Corte a Portugal, pois poder-se-ia supor que adotáramos um critério meramente político numa pesquisa cultural. Para nós tal data não possui qualquer conotação política; ela significa apenas uma diminuição sensível do público comprador das obras em circulação.

A base documental da nossa pesquisa não é muito variada nem abundante, mas foi trabalhada exaustivamente: os "avisos" da $\mathrm{Ga}$ zeta do Rio de Janeiro, a publicação periódica $O$ Patriota, a "Notícia do Catálogo de Livros", que se achavam à venda na loja de Manuel Antônio da Silva Serva, impressa no Rio de Janeiro em 1811, as publicações da Impressão Régia, a correspondência de Luís Joaquim dos Santos Marrocos (3) e a legislação referente à imprensa .

Vários problemas, contudo, nos surgiram na análise desse material. Quando procedemos a uma leitura exaustiva dos anúncios de livros na Gazeta, constatamos que o anunciante mais importante, o livreiro da loja da Gazeta, fazia uma separação gráfica e linguística entre os livros que "saíam à luz" e aqueles que "se achavam à venda", muito embora a classe dos primeiros estivesse naturalmente inserida na dos segundos. A estrutura do anúncio, repetida em todos os números do periódico, fornece-nos deste modo duas séries paralelas e aparentemente independentes uma da outra: numa os textos publicados na Corte, na outra os livros à venda, que incluiam os importados da metrópole. Não nos teríamos certamente detido neste problema das duas séries, se não fossem elas as responsáveis por certos erros cometidos por Alfredo do Vale Cabral nos Anais da Imprensa Nacional do Rio de Janeiro de 1808 a 1822 (Rio de Janeiro, 1881).

Nas páginas introdutórias do seu trabalho, aliás notável e de grande utilidade, Vale Cabral declara que, quando não conseguiu ver exemplares das obras saídas dos prelos da Impressão Régia do Rio (pois muitas delas já não se encontravam mais nas bibliotecas brasileiras) indicou as fontes de onde extraiu as respectivas notícias. Ora há obras que aparecem no seu levantamento cuja fonte informadora é apenas a Gazeta do Rio de Janeiro. E' o caso das novelas Lausus e Lâdia, $O$ combate das paixóes, $A$ amante militar e ainda do Recreio doméstico, ou ramalhete de novelas, contos, histórias, vida dos grandes homens, etc., obras anunciadas na Gazeta do Rio e de 6 de ju-

(3). - Anais da Biblioteca Nacional do Rio de Janeiro, vol. 56, R:o de Janeiro, 1939 . 
lho de 1816. E todas já tinham sido anunciadas nas Gazetas de Lisboa como tendo saído à luz na metrópole ( 6 de janeiro, 1 de fevereiro, 9 de fevereiro, 13 de fevereiro de 1816). E' pouco provável que houvesse outra edição carioca dos mesmos textos, no mesmo ano e com pouco intervalo de tempo, tanto mais que o custo da impressão era mais elevado no Rio do que em Lisboa. Enquanto não virmos edições destas obras com a indicação de terem sido impressas no Rio (possível que a Biblioteca Nacional de Lisboa possua algum exemplar), continuaremos a acreditar que estas novelas, recém-publicadas em .Lisboa, foram importadas e postas à venda na loja da Gazeta.

Vale Cabral deve ter seguido à letra a separação nos anúncios de livros e considerado como impressos no Rio todos os que pertencem à série dos "saídos à luz", sem ter o cuidado de comparar com as informações fornecidas pelas Gazetas de Lisboa.

A lista levantada por Vale Cabral, salvo esta pequena restrição, é extremamente útil e permite isolar, na massa dos livros anunciados, os editados pela Impressão Régia carioca, e além disso fornece, na maior parte dos casos, o título completo da obra e o nome do sel autor, dados que nem sempre se encontram nos anúncios da Gazeta. Quanto às obras importadas a identificação é por vezes difícil, quando o nome do autor não é indicado ou quando se trata de folhetos anônimos. Já conseguimos contudo identificar 450 títulos, mas como não existe uma obra portuguesa equivalente, para o período em estudo, do Dictionnaire des ouvrages anonymes de Barbier, cremos que muitas obras de devoção (novenas, livrinhos de oração, exercícios, ctc.), novelas e contos, comédia se entremezes, cartilhas didáticas $\mathrm{e}$ textos políticos de circunstância, permanecerão por identificar.

A identificação das obras em circulação é o primeiro passo a ser dado, o mais demorado e trabalhoso, mas sem ele a pesquisa não pode progredir, pois o título resumido que aparece nos anúncios e catálogos de livreiros não é suficiente para o historiador da cultura proceder a uma classificação das obras por gêneros e avaliar a importtância como $A$ arte da guerra seria possivelmente incluido nos livros militares; trata-se contudo de um poema escrito por Frederico II da Prússia, devendo portanto ser inserido na classe Belas Letras.

Quanto à identificação das obras cm língua estrangeira, principalmente em francês, o problema maior que surge resulta do fato de os livreiros preferirem anunciar esses livros com o título traduzido em português. 


\section{A produção de livros: a Impressão Régia.}

Atendendo à necessidade de uma oficina de impressão no Brasil, o Regente D. João estabeleceu uma Tipografia Real com os prelos vindos de Portugal, na qual seria impressa toda a legislação e também os papéis que emanassem de qualquer das repartições (4). $\mathrm{Na}$ nossa análise não levaremos em considetação esta produção burocrá: tica e examinaremos apenas as obras e folhetos publicados sem esse caráter de divulgação das medidas governamentais.

Dizia o decreto da criação da Impressão Régia que nela se podiam imprimir "todas e quaisquer outras obras". Deixando de lado o problema da censura, que tem sido várias vezes estudado pelos historiadores da cultura brasileira, deter-nos-emos no processo de produção do livro. O custo da impressão dos papéis oficiais era coberto pelos cofres do Estado, mas não haveria obras encomendadas e pagas pelo governo? Um documento alude a essa possibilidade. A propósito de uma publicação contra os pedreiros livres, o conde de $\mathrm{Li}$ nhares escreveu a José Bernardes de Castro, da Junta Diretora da Impressão Régia:

“... sendo o folheto junto cheio de obscenidades, e não combatendo como era de esperar os falsos princípios e péssimas consequências, a ridícula seita dos pedreiros livres, deve ao menos deixar-se conhecer ao público que é obra que o governo consentiu que se imprimisse, mas que não mandou imprimir, e eu me lisongeio de que $\mathrm{Vm}$. não imprimiu tal folheto por conta da Impressão Régia" (5).

Havia portanto obras custeadas pelo Estado. Mas quando isso não acontecia, quem pagava o custo da produção do livro? A edição da Corografia Brasílica foi paga pelo seu autor através do processo de subscrição, como podemos ver pelo seguinte anúncio na Gazeta do Rio de Janeiro em 1815:

"Esta obra tão útil, e tão desejada, se acha já pronta para a impressão, que ocupará 700 páginas de quarto, pouco mais uu menos, e se oferece à subscrição; e os senhores que quiserenı subscrever, depositarão por cada exemplar 1:600 réis, na loja de Manuel Mandilo, defronte de N. S. do Carmo".

(4). - Decreto de 13 de maio de 1808.

(5). - Secretaria da Guerra, 14 de dezembro de 1809, Conde de Linhares a José Bernardes de Castro. 
A lista que acompanha a edição dá-nos um total de 93 subscritores e de 133 exemplares subscritos, e era com este capital inicial que o autor financiava a sua obra.

Mas ele precisava de uma garantia governamental de que ninguém mais a poderia imprimir, e daí o requerimento de privilégio feito ao rei. Vejamos em que termos foi concedido:

"Hei por bem conceder ao suplicante privilégio exclusivo for tempo de catorze anos consecutivos, contados da data deste, para que nenhum livreiro, impressor, ou outra qualquer pessoa possa vender, imprimir ou mandar vir de fora dos meus reinos e domínios a dita obra intitulada Corografia Brasílica, debaixu da pena de perderem todos os exemplares dela, que lhes foram achados, metade para o denunciante, e outra metade para os cativis. E hei outrossim por bem, que o mesmo privilégio possa por moite do suplicante passar aos seus herdeiros, ou a quem ele o deixar, contanto que não exceda o espaço dos ditos catorze anos concedidos" (alvará de 21 de maio de 1817).

Além do padre Aires do Casal, Monsenhor Pizarro também financiou a sua obra por meio do processo da subscrição, como vemos no prospecto das Memórias históricas do Rio de Janeiro:

"Pretende o autor das memórias sobreditas levá-las à estampa, rogando por isso ao público assaz distinto (em utilidade de quem se desvelou) queira prestar-lhe o seu honroso obséquio da assinatura de $8 \$ 000$ réis $(6)$.

Os assinantes deveriam pagar logo esta quantia, ou então quando recebessem nos livreiros o primeiro volume da obra. O sistema da subscrição permite-nos compreender a importância de que se revestiu na época o prospecto, meio utilizado para, através de uma argumentação a favor do interesse e da utilidade da obra, angariar as assinaturas suficientes para garantir a edição. Depreende-se de alguns prospectos que, no caso de não haver subscritos em número conveniente, a obra não sairia à luz.

Estes autores-editores, que nos aparecem no Rio de Janeiro no início do século XIX, tinham sido muito comuns no século XVIII, e Diderot, na sua memória Sur la liberté de presse, analisa uma situação que a seus olhos nada tinha de agradável:

(6). - Gazeta do Rio de Janeiro, n० 73 de 1819 . 
"Escrevi e várias vezes imprimi por minha conta. E posso afirmar, de passagem, que nada se conjuga pior do que a vida ativa do comerciante e a vida sedentária do homem de letras. Incapazes que somos de uma infinidade de pequenas tarefas, em cem autores que pretenderem explorar por si próprios as suas obras, haverá 99 que se sairão mal e se enfastirão de tal atividade" (7).

Ignoramos se no Rio de Janeiro os livreiros se atribuiam a função de editores. E' possível que algum fornecesse o capital necéssário para a impressão de livros e folhetos, mas até agora não encontramos nenhum vestígio dessa atividade. Também não encontramos traços de nenhuma "sociedade de editores" como aquela a que se refere Marrocos a propósito de uma obra publicada em Lisboa em 1817 e por tele distribuida no Rio de Janeiro. $\mathrm{Na}$ sua correspondência alude a desentendimentos financeiros entre o autor dessa obra, Pedro José de Figueiredo, e a dita sociedade de editores:

"não posso atribuir a Figueiredo privilégio algum para receber o dinheiro sem consentimento da sociedade em geral, e sua delegação como procurador ou tesoureiro; e se por acaso cia lhe deve, ou tem comido dele, a ninguém é lícito o pagar-se por suas mãos" (8).

Quer dizer que a situação do autor era sempre difícil, tanto na posição de editor quanto na de simples produtor intelectual...

Quando começamos a pesquisar estas questões relativas à produção do livro, tínhamos em mente o problema da tiragem das obras, mas não obtivemos qualquer informação sobre este assunto. A unica referência que encontramos diz respeito à produção francesa, e não à carioca ou mesmo portuguesa. A loja da Gazetaĺ anunciada a "mui moderna obra" impressa em Londres em 1814, traduzida em português, De Bonaparte e dos Bourbons, e da necessidade de nos unirmos ao snossos legítimos príncipes, para a felicidade da França e da Europa, por Chateaubriand e o anunciante acrescentava:

"Para mostrar decididamente o elogio desta produção, bastará dizer que no decurso de alguns meses se venderam cinquenta e tantos mil exemplares em Paris".

(7). - Editions sociales, Paris, 1964, p. 45.

(8). - Ob. cit., carta $\mathrm{n}^{\circ} 162$. 
O que pressupõe ou uma grande tiragem ou uma sucessão muito rápida de edições.

A mesma ausência de informação sobre a tiragem foi constatada pelos pesquisadores da Ecole Pratique des Hautes Etudes que realizam uma pesquisa sobre o livro na sociedade francesa do século XVIII, a qual nos inspiramos para este trabalho, e Julien Brancolini e Marie-Thérèze Bouyssy, no início do seu estudo sobre a vida provinciana do livro do fim do Antigo Regime, comentam:

"Uma grande incógnita paira sobre o nosso conhecimento da difusão do livro no século XVIII: a ausência de dados numéricos referentes às tiragens" (9).

$\mathrm{Na}$ produção da tipografia régia do Rio de Janeiro que generos predominavam? Para se avaliar a importância relativa dos generos, torna-se necessário adotar a classificação utilizada na época, por exemplo nas bibliotecas públicas de classificação atual. Deverão portanto as obras ser separadas nas seguintes classes que o século XIX nascente herdou do século anterior: Belas Letras, Teologia, Ciências e Artes, História e Jurisprudência. Estas são as grandes classes, que comportam naturalmente várias subdivisões.

Não vamos proceder, no âmbito limitado deste artigo, à análise quantitativa da produção da Impressão Régia durante o período de 1808 a 1821 , pois isso será objeto de um trabalho mais amplo. Queremos apenas chamar a atenção para o fato desse estudo quantitativo não ser por si só esclarecedor, exigindo ser completado pela análise de conteúdo de cada uma das obras que ainda hoje existem. Sem lermos esses textos que restam, corremos o risco de errar uma classificação baseada apenas nos títulos. Além disso é preciso levar em conta o "peso" respectivo de cada obra dentro do genero a que pertence, elemento desprezado pelo estudo unicamente quantitativo, que nivela, por exemplo, o tratado de álgebra em vários volumes e a pequena cartilha para aprender a contar.

Entre os livros publicados pela tipografia régia do Rio incluemse muitas obras que já tinham sido editadas em Lisboa alguns anos antes, quer originais portugueses quer traduções. Os inéditos publicados pertenciam na sua maioria às classes de Ciências e Artes e de Belas Letras. Contudo os primeiros anos de atividade da Impressão Régia foram marcados pela publicação de textos políticos (reimpres-

(9). - Livre et société dans la France du XVIII e siècle, Paris, 1970, tomo II, p. 3. 
sōes ou originais) que poderiam ser agrupados sob a designação de "ciclo napoleônico" e que se ligavam, de uma maneira polêmica e por vezes satírica, à situação política européia .

O custo da impressão no Rio era elevado, comparativamente à Bahia e Lisboa, segundo depreendemos da correspondência de Marrocos, que comenta numa carta a seu pai, residente em Lisboa:

“. . Faria aqui negócio Simão Tadeu, se fizesse aqui estabelecer seu irmão com um bom preto, pelos preços còmolios daí; ou pouca diferença, só para deitar por terra este ladrä́n da Impressão Régia (...). Vários negociantes para fazerem públicas as suas fazendas para os leilóes do estilo, mandam à Bahia imprimir as suas listas, pois lhes não convém fazer estes gastos ridículos" (10).

\section{A distribuição dos livros.}

As referências de viajantes como $T$. von Leithold, ou me-mo a correspondência de um residente como Marrocos, levar-nos-iam a supor um comércio de livros inferior ao que realmente existia no Rio de Janeiro e que ficamos conhecendo através dos anúncios da Gazeta. O primeiro chega a afirmar que no Rio não havia livreiros, embora se encontrassem comerciantes de gravuras; e o segundo escrevia em 1813:

"Aqui há pouco negócio de livros, e dois livreiros, que aqui se acham, basta serem franceses para serem tratantes" (11).

Referência a João Roberto Bourgeois e a Paulo Martin, pois o outro francês livreiro, Borel, saira do Rio em 1812.

Para uma cidade como o Rio de Janeiro no início do século XIX, não se pode dizer que fossem poucos os mercadores de livros: em 1808 Francisco Luís Saturnino da Veiga e Manuel Jorge da Silva já aparecem anunciando na Gazeta; em 1810, Manuel Mandilo, com loja na rua Direita, defronte do Carmo, e Manuel Joaquim da Silva Porto, na rua da Quitanda, à esquina da de São Pedro. E outros livreiros faziam ainda publicidade das obras à venda nas suas loias no período que se estende até 1821: João Batista dos Santos, Jerônimo

(10). - Ob. cit., carta $\mathrm{n}^{\circ} 9$.

(11). - Ob. cit., carta $n^{9} 56$. 
Gonçalves Magalhães, Francisco José Nicolau Mandilo e José Antônio da Silva, constando nesta enumeração apenas os nomes daqueles que surgem acompanhados de uma referência explícita ao comércio de livros ("livreiro", "mercador de livros", "com loja de livros", etc.). Outras pessoas anunciavam livros para vender, mas, ou se tratava de particulares que vendiam obras em segunda mão, ou se tratava de outros comerciantes que acidentalmente vendiam alguns livros, como boticários, importadores franceses, etc.

Além dos mercadores de livros radicados no Rio, havia ainda aqueles que vinham de outras cidades vender livros à Corte, por exemplo, Manuel Antônio da Silva Serva, livreiro com tipografia na Bahia, e que em $1811 \mathrm{fez}$ imprimir na tipografia régia um catálogo de todas as obras que trouxera para vender durante a sua permanência no Rio. Este catálogo constitui o elemento mais precioso que o historiador da cultura poderia encontrar, muito embora exija um minucioso trabalho de identificação de obras que são indicadas sem o mínimo rigor, quer no que diz respeito ao título, quer em relação ao autor. Dois dados importantes são fornecidos por este catálogo: o formato dos livros e o seu preço, que analisamos apenas em relação à primeira parte da lista, composta de livros em sua maioria encadernados, deixando para uma análise posterior a longa lista de

"papéis pertencentes a notícias, proclamaçōes, e tudo quarto pertence às guerras, tragédias, e novelas tudo em brochura"

No século XVIII a brochura era desprezada enquanto produৎ̧ão tipográfica e cultural. No respectivo verbete da Encyclopédia de Diderot e d'Alembert há uma referência explícita à má qualidade desta nova produção, cuja leitura tinha como consequência dois males:

\footnotetext{
"um, corromper o gosto; outro, gastar tempo e dinheiro que se poderiam consagrar a livros mais sólidos e instrutivos".
}

A abundância de brochuras era encarada como uma "frivolidade do século", cuja única vantagem era fazer viver alguns autores menores e ativar a circulação dos papéis impressos:

"Uma brochura passa da alcova de uma dona para a sua antecâmara, e esta circulação renova-se, e faz valer o comércio das nossas fábricas".

Consumidas por um público feminino quando veiculavam novelas, ou por um público masculino quando informavam ou se refe- 
riam aos acontecimentos políticos, as brochuras caracterizavam-se ainda no início do século XIX pelo seu caráter efêmero, eram papéis que, na expres:ão de Diderot, "brotavam e pereciam no mesmo dia".

Quanto ao formato dos livros, em 439 títulos anunciados no catálogo, 197 eram in $8 .^{\circ}, 107$ in $4 .^{\circ}$, e os in-folio eram apenas 37 , sendo os outros formatos ainda mais raros. Quanto ao preço, a maior porcentagem encontrava-se entre 600 e 700 réis (122 títulos em 439) e acima de $1 \$ 000$ (114 em 439). Para termos uma idéia mais correta do significado destes preços, damos aqui alguns exemplos de outros preços de mercadorias variadas, pois só assim podemos avaliar se a maior parte dos volumes à venda eram caros ou não.

Mercadoria.
lirguiça
papel branco
rapé francês
empada de recheio de ave
água antifebril
graxa inglesa
tinta para escrever
aguardente de anis
papel almaço
vestido de senhora
chapéu de senhora

\begin{tabular}{|c|c|c|}
\hline $\begin{array}{l}\text { Unidade de venda. } \\
\text { arrátel }\end{array}$ & $\begin{array}{l}\text { Progr } \\
280\end{array}$ & \\
\hline resma & $5 \$ 760$ & $"$ \\
\hline libra & $1 \$ 200$ & $"$ \\
\hline cada & 100 & $"$ \\
\hline garrafa & $1 \$ 000$ & $"$ \\
\hline garrafa ou pote & 320 & $\because$ \\
\hline quartilho & 320 & $"$ \\
\hline arrafa & 560 & $"$ \\
\hline ala & $2 \$ 000$ & " \\
\hline $\mathrm{da}$ & $16 \$ 000$ & $\bullet$ \\
\hline $\mathrm{da}$ & $6 \$ 0(: 1)$ & $"$ \\
\hline
\end{tabular}

O livro comum custava o mesmo que um jantar numa casa de pasto, mas aquilo que poderíamo" denominar "literatura de cordel" como comédias, entremezes e novelas, em brochura, custava menos de 100 réis, devendo ser lucrativa a venda destes folhetos, pois o livreiro Silva Serva não hesitou em inclui-los no seu catálogo, gastando com isso algumas páginas de impressão cara. Marrocos, em sua correspondência, depois de referir a dificuldade de conseguir subscritores para uma obra publicada em Lisboa e cujo preço era considerado elevado, acrescenta:

\section{"tudo o que passa de 480 ou 800 réis é dificultoso achar quem queira dispender por este modo" (12).}

Encontramos um único anúncio de livros em saldo, ou, como então se dizia, com "rebate dos preços", quando a mercadoria que se encontrava à venda na loja do livreiro Manuel Mandilo pas ou a ser

$$
\text { (12). - Ob. cit., carta } \mathrm{n}^{\mathfrak{P}} 151 \text {. }
$$


vendida numa loja de vidros (13). Quanto ao preço dos livros em segunda mão, vendidos por particulares, não obtivemos qualquer informação.

A distribuição e venda de livros nem sempre era feita por mercadores especializados, principalmente quando se tratava de obras importadas de Lisboa, pois os próprios autores e editores que tinham conhecidos ou amigos no Rio de Janeiro pediam a estes que se encarregassem de sua "extração". Marrocos, por exemplo, empregado público, por duas vezes se incumbe de distribuir e vender publicações portuguesas, e nerte ponto a sua correspondência constitui um documento importante para o conhecimento desse processo. A obra, Retratos, e elogios dos varóes, e donas, da qual Marrocos conseguira apenas vender 35 exemplares, rendera $340 \$ 200$ réis. Ora a lista das despe as fôra a seguinte:

$\begin{array}{lr}\text { Frete do pacote, de Lisboa para o Rio de Janeiro } & 3 \$ 270 \text { réis } \\ \text { Despesas na Alfândega } & 3 \$ 150 ", \\ \text { Condução por mar e por terra } & 1 \$ 600 ", \\ \text { Anúncios na Gazeta } & 2 \$ 400 \text { " } \\ \text { Ao distribuidor dos anúncios em } 4^{\circ} \text { pelos assinan- } & \\ \text { tes da Gazeta } & \$ 960 " \\ \text { Comissão e } 27 \text { exemplares a } 970 \text { réis cada um } & 26 \$ 190 " \\ & 37 \$ 570 "\end{array}$

Nesta lista de despesas alguns pontos surgem como enigmáticos: se tinham sido vendidos 35 exemplares por que razão se pagara apenas a comissão de 27 ? Se a obra fôra anunciada na Gazeta, por que nos aparece um distribuidor dos anúncios?

O primeiro enigma é de fácil solução. Inicialmente Marrocos pedira ao Padre Joaquim Damazo, bibliotecário da Livraria Régia, para distribuir a obra pelos livreiros (14), mas em seguida queixa-se do "desmazelo ou negligência" destes em conseguir subscritores para a obra e resolve mudar de processo:

"resolvi-me a procurar subscrições pelas mesmas casas, incumbindo desta diligência um sugeito a quem tenho pago dê comissão os mesmos 10 por 100 que pagaria aos livreiros, se se continuassem ali a vender" (15).

(13). - Gazeta do Rio de Janeiro, $\mathrm{n}^{\circ} 57$ de 1814.

(14). - Ob. cit., carta $n^{\circ} 144$.

(15). - Ob. cit., carta $n^{\circ} 153$. 
Quando remeteu a folha das despesas para Lisboa, tinha já pago a comisão dos livros vendidos pelo agente, mas não daqueles que tinham sido vendidos pelos livreiros, e assim se explica o aparente enigma .

Não conseguimos contudo recolver o segundo problema. Os anúncios da Gazeta constituiram a base documental para o nosso estudo, mas não vimos qualquer referência a um "distribuidor dos anúncios em $4 .^{\circ}$ pelos assinantes da Gazeta". Limitamo-nos aqui a aventar uma hipótese: que por vezes os anúncios não saissem no próprio corpo do periódico e que fossem impressos à parte, in $4 .^{\circ}$, e distribuidos então pelos assinantes do jornal. Isso verifica-se por exemplo com prospectos de obras publicadas pela Imprersão Réơia ou com anúncios mais extensos de lojas que vendiam mercadorias variadas e de importação.

Esta venda pelas casas dependia fundamentalmente da habilidade do agente. Marrocos despediu o dele por não ter o devido cuidado no manuseio dos livros com estampas, e lamentava-se por ainda não ter encontrado outro:

"Seu eu tivesse aqui pessoa capaz e desembaraçada para solicitar subscritores, estou certo que se grangeariam mais de 500 ou 600 , e todos pessoas graudas, o que faria aumentar o crédito da obra" (16).

Marrocos não admitia sequer a possibilidade de fazer ele próprio esse serviço e ganhar a comissão, pois tal atividade não se coadunaria com a sua posição de empregado público:

"eu o não posso fazer pessoalmente, pois nem tenho gsito nem tempo para isso, e além de me não ser isso decente nás circunstâncias em que me acho, não tenho olhos para ver arreganhar os dentes a uns, e torcer o nariz a outros" (17).

As obras à venda no Rio de Janeiro e não publicadas nesta cidade vinham principalmente de Lirboa, e também da Bahia e Porto, e, em escala mais reduzida, de França, sendo a importação do livro francês menor do que seria de supor, dado o peso da cultura francesa na época. Mas isso se explica pelo fato de a penetração das formas literárias ou dos escritos científicos se fazer principalmente

(16). - Ob. cit., carta $\mathrm{n}^{\circ} 155$.

(17). - Ibidem. 
através de traduções que eram abundantes na metrópole. O livro inglês era praticamente inexistente no comércio do Rio, e o alemão só aparece esporadicamente nos anúncios, sempre em versões bilíngues. Lisboa era o grande centro fornecedor e se compararmos a publicidode da Gazeta do Rio com a da Gazeta de Lisboa constataremos que eram praticamente as mesmas obras que se vendiam numa e noutra cidade.

\section{O consumo de livros.}

Divergindo da linha seguida por Lukács e Goldmann, os sociólogos da literatura pertencentes à chamada "escola de Bordéus", cujo principal representante é Robert Escarpit, preocuparam-se, nestes últimos anos, mais com a análise do público do que com o autor ou a obra.

A noção de público deve contudo ser subdividida, a fim de não se confundir o público ideal ou imaginário com o público real. Qualquer autor ao escrever se dirige a um determinado público, cuja imagem preside ao ato de criação da obra. Mas entre estes leitores imaginários, visados pelo autor, e os leitores reais, surge por vezes uma tal discrepância que se torna necersária a utilização de méotdos diferentes na análise de cada um deles.

Quanto ao público imaginário, é a própria obra que constitui o espaço onde se deverá realizar a pesquisa. Temos um exemplo deste tipo de análise na comunicação de Claude Perrus ao Colóquio de Cluny de 1970, Remarques sur les rapports entre écrivain et publi: dans le Décaméron de Boccace, e para toda a produção da Impressão Régia do Rio de Janeiro se pode fazer um estudo dos públicos que os vários autores tinham em mente ao redigirem seus textos. Mas a análise deste público não pertence propriamente à sociologia da leitura, e nela o historiador e o sociólogo encontram-se lado a lado, munidos dos mesmos instrumentos de trabalho e de materiais de valor idêntico.

Já o mesmo não se verifica no estudo do público real. Aqui a vantagem do sociólogo é muito grande, na medida em que tem ao seu alcance os vários grupos de leitores que pretende analisar. Basta elaborar questionários bem feitos e aplicá-los, como fez por exemplo a equipe do Centro de Sociologia dos fatos literários no Centro de seleção militar de Limoges em 1963, ao propor-se averiguar, junto aos recrutas de escolaridade diferente, os cinco autores mais conhecidos . Ora o público real que o historiador pretende estudar não pode 
mais ser questionado e portanto só por processos indiretos se chegará a obter alguns resultados, necessariamente fragmentários.

Uma das maneiras indiretas de se conhecer o público do Rio de Janeiro consiste em examinar e discriminar as formas de publicidade utilizadas na Gazeta, pois elas nos revelam os gostos e preferências da época. Constatamos deste modo que a publicidade de autor era menos empregada do que a de genero, sendo raros os escritores que tinham um público suficientemente seguro para poderem servir de chamariz aos livreiros. Podemos citar apenas José Acúrsio das Neves, Boccage, o Pe. José Agostinho de Macedo, José Daniel Rodrigues da Costa. De resto toda a publicidade se organizava em torno do gosto do público por um determinado genero, havendo anúncios só para novelas, ou peças dramáticas, obras jurídicas, militares, de medicina ou farmácia, etc. Outras vezes percebemos que havia simplesmente um público de novidades, pois muitos livreiros acentuam apenas a modernidade das obras à venda nas suas lojas.

No público real é metodologicamente conveniente distinguir os leitores dos compradores, como faz Robert Escarpit em Sociologie de la littérature, chamando a atenção para o fato de que, no processo de produção, distribuição e consumo do livro, o comprador é um elemento importante, mesmo que não leia os textos que adquire.

Para se estudar esses compradores, de uma perspectiva puramente quantitativa ou simultâneamente quantitativa e sociológica, ainda hoje a sociologia do público depara com graves dificuldades, na medida em que editores e livreiros se mostram pouco interessados na divulgação desses dados, ou então, por estarem organizados ainda de uma maneira muito primitiva, nem mesmo os possuem. Estes problemas sel agravam numa história sociológica do público, pois aqui há poucas perspectivas de progresso, uma vez que a documentação não fornece nem indiretamente tais informações. A não ser de uma maneira muito fragmentária e incompleta através das listas de subscritores, publicadas em muitas obras.

Vimos já, ao expormos o processo de produção do livro, que era gera'mente o autor que mandava imprimir suas próprias obras, graças a um capital inicial fornecido pelos subscritores. Em que grupos sociais eram estes recrutados? Aparecem sempre nas listas alguns nobres, eclesiásticos, empregados de uma ou outra repartição do Estado, alguns comerciantes mais conhecidos, mas há ainda a ma'sa dos anônimos, daqueles compradores cujos nomes o historiador não está habituado a encontrar na sua documentação e que portanto permanecem sem classificação social. Seria interessante conhecer a idade 
de'se público de subscritores, saber se era o homem maduro ou o jovem que comprava mais livros, mas também aqui a massa dos anônimos nos impede de levar a pesquisa muito longe.

A análise do público real implica a colocação de um outro problema: que tipo de leitura era feito? O leitor comum mais uma vez foge à área do nosso controle e resta-nos uma categoria especial de leitor, a daquele que comenta as obras em jornais literários.

Como no Rio de Janeiro do início do século passado se imprimia apenas um jornal literário, $O$ Patriota, e como mesmo este foi de curta duração (1813-1814), cabe-nos apenas examinar o tipo de resenha literária feita pelo seu redator, Manuel Ferreira de Araújo Guimarães, autor e tradutor de vários compêndios de matemática. Este redator, contudo, só comentava as obras que iam saindo dos prelos da Impressão Régia do Rio, sem fazer qualquer referência às novidades importadas, e as suas notas continham quase exclusivamente um resumo da obra, acompanhado de elogios mais ou menos eloquentes. Com uma única exceção: a maneira como criticou $O$ jurainento dos numes, drama escrito para ser representado no Real Teatro de São João e da autoria de D. Gastão Fausto da Câmara Coutivho, provocou uma polêmica com o autor, a qual girou em torno de uma teoria dos generos. Discutiu-se o que se devia entender por poema dramático e poema lírico, apoiando-se o redator do $O$ Patriota na autoridade da Enciclopédia metódica, ou seja na Encyclopédia raisonnée de Diderot e d'Alembert, visto tratar-se de uma obra

"conhecida e respeitada pelos eruditos, e ilustrada com os nomes de sábios consumados" (18).

Vemos portanto que a leitura feita por um leitor privilegiado, que corresponderia hoje ao crítico literário, era um ato que implicava apenas a comparação de uma determinada produção com o modelo fornecido pelo genero. Os textos eram classificados e inseridos na classe competente, visando a leitura crítica apenas a constatação ou a ausência da obediência às normas impostas pelo genero correspondente. 66-7.

(18). - O Patriota, $\mathrm{n}^{\circ} 1,3^{\text {a }}$ subscrição, janeiro e fevereiro de $1814, \mathrm{p}$. 


\section{Conclusão.}

Hoje o sociólogo da literatura dispõe de um conjunto de meios e técnicas para abordar os aspectos coletivos do "fenômeno livro"; mas o historiador que pretender estudar uma época e uma sociedade através dos seus livros ver-se-á obrigado a agir por caminhos indiretos e por desvios. Foi o que fizemos neste pequeno trabalho, que constitui apenas uma parte de uma pesquisa mais ampla que iniciámos há dois anos. Quer num estudo mais restrito quer noutro mais vasto, os problemas são contudo os mesmos. $\mathbf{O}$ historiador precisa se encontrar fontes ou, para sermos mais rigorosos, precisa de constituir fontes capazes de responder a perguntas idênticas às do sociólogo do livro. O que se passa nesta área da história da cultura verificouse também na história econômica, quando os historiadores se inspiraram nos trabalhos dos economistas para as suas pesquisas. Como escreve Frédéric Mauro em Nova História e Novo Mundo, os vestígios deixados pelo passado, por mais ricos que sejam, continuam insuficientes em comparação com a documentação oferecida pelo mundo em que vivemos. As leis econômicas são quantitativas e a sua verificação pressupõe dados estatísticos que quase não existem em relação ao passado.

"Muito frequentemente o historiador é obrigado a extrair sua estatística de documentos que não previam tal uso" (19).

mas estas dificuldades não o impedem de questionar o passado em função de perguntas que hoje são importantes.

$\mathrm{Na}$ história da cultura observam-se nestes últimos anos problemas metodológicos semelhantes aos que a história econômica teve de enfrentar, uma vez que o historiador não está mais interessado numa visão valorativa ou ufanista da cultura, mas sim em conhecê-la e descrevê-la: o nome de Monte Alverne é menos importante do que o sermão como gênero, estudado do ponto de vista quantitativo em relação a outros gêneros da produção livresca da época e do ponto de vista estrutural quanto aos seus elementos constitutivos e relações que estes mantém entre si; a criação da Impressão Régia no Rio só adquire significado cultural depois de analisado o seu modo de produção do livro e de estudado o conteúdo de cada uma das obras ou textos por ela publicados.

Os problemas metodológicos e o pluralismo de métodos empregados constituem contudo um bom sinal: indicam a fase de renovação por que passa atualmente a história da cultura.

(19). - Ob. cit., p. 16. 